\title{
Passive air sampling of gaseous elemental mercury: a critical review
}

\author{
David S. McLagan, Maxwell E. E. Mazur, Carl P. J. Mitchell, and Frank Wania \\ Department of Physical and Environmental Sciences, University of Toronto Scarborough, Toronto, Ontario, Canada \\ Correspondence to: Frank Wania (frank.wania@utoronto.ca) and Carl P. J. Mitchell (carl.mitchell@utoronto.ca)
}

Received: 5 November 2015 - Published in Atmos. Chem. Phys. Discuss.: 10 December 2015

Revised: 17 February 2016 - Accepted: 23 February 2016 - Published: 9 March 2016

\begin{abstract}
Because gaseous elemental mercury (GEM) is distributed globally through the atmosphere, reliable means of measuring its concentrations in air are important. Passive air samplers (PASs), designed to be cheap, simple to operate, and to work without electricity, could provide an alternative to established active sampling techniques in applications such as (1) long-term monitoring of atmospheric GEM levels in remote regions and in developing countries, (2) atmospheric mercury source identification and characterization through finely resolved spatial mapping, and (3) the recording of personal exposure to GEM. An effective GEM PAS requires a tightly constrained sampling rate, a large and stable uptake capacity, and a sensitive analytical technique. None of the GEM PASs developed to date achieve levels of accuracy and precision sufficient for the reliable determination of background concentrations over extended deployments. This is due to (1) sampling rates that vary due to meteorological factors and manufacturing inconsistencies, and/or (2) an often low, irreproducible and/or unstable uptake capacity of the employed sorbents. While we identify shortcomings of existing GEM PAS, we also reveal potential routes to overcome those difficulties. Activated carbon and nanostructured metal surfaces hold promise as effective sorbents. Sampler designs incorporating diffusive barriers should be able to notably reduce the influence of wind on sampling rates.
\end{abstract}

\section{Introduction}

Mercury $(\mathrm{Hg})$ is a contaminant of global concern, undergoing long-range atmospheric transport (LRAT) and deposition in remote ecosystems (Driscoll et al., 2013; Selin, 2009; Selin et al., 2007). Once deposited, inorganic Hg can be transformed to methylmercury $(\mathrm{MeHg})$ through the activity of certain anaerobic microbes (Driscoll et al., 2013; Schroeder and Munthe, 1998; Selin, 2009). In both humans and wildlife $\mathrm{MeHg}$ is bioaccumulative and a potent neurotoxin (Driscoll et al., 2013; Scheuhammer et al., 2007; Wolfe et al., 1998) and at lower chronic exposure has also been associated with reproductive impairments (Scheuhammer et al., 2007; Selin, 2009) and geno- and immunotoxicity (Wolfe et al., 1998). The major uptake pathway of MeHg for humans is through the consumption of fish and seafood (Driscoll et al., 2013; Selin, 2009; Pirrone et al., 2013). Hence, elevated $\mathrm{Hg}$ exposure is prevalent among human populations with high fish consumption (Driscoll et al., 2013; Johansen et al., 2007; Selin, 2009). Although MeHg is the most bioaccumulative form of $\mathrm{Hg}$, all forms exhibit toxic effects on mammals, the degree of which depends on species, dose, time, and route of exposure (Harari et al., 2012).

Within the global biogeochemical cycle of $\mathrm{Hg}$, natural sources to the atmosphere include geological processes and evasion from surfaces, with the ultimate sink being burial in deep ocean sediment (Driscoll et al., 2013; Schroeder and Munthe, 1998; Selin, 2009). The Hg cycle is being disrupted by primary anthropogenic emissions, estimated to range from 1900 to $4000 \mathrm{Mg} \mathrm{yr}^{-1}$ (AMAP, 2011; AMAP/UNEP, 2013; Selin, 2009, and references therein). Primary anthropogenic sources of $\mathrm{Hg}$ can be from both the direct use of $\mathrm{Hg}$ or its emission as a by-product and include coal combustion, waste disposal, artisanal gold mining, cremation of deceased bodies containing Hg-based dental fillings, and the production of cement, nonferrous metals, iron, steel, caustic soda, gold, and Hg itself (Driscoll et al., 2013; Selin, 2009; Zielonka et al., 2012). 
There are three forms of atmospheric Hg: gaseous elemental mercury (GEM), gaseous oxidized mercury (GOM), and particle bound mercury (PBM). The mean ambient concentration of total gaseous mercury (TGM; made up of GEM and GOM) is approximately $1.3-1.7$ and $1.1-1.3 \mathrm{ng} \mathrm{m}^{-3}$ in the Northern and Southern hemispheres respectively (Dommergue et al., 2010; Sprovieri et al., 2010; Driscoll et al., 2013; Gustin et al., 2011; Luo et al., 2010; Selin, 2009; Selin et al., 2007), with higher levels in urban areas and close to sources (Cheng et al., 2014; Carpi, 1997; Zhang and Wong, 2007). GEM's relatively high vapour pressure and inertness to atmospheric oxidation leads to a long atmospheric residence time of approximately 1 year (Lin et al., 2006; Pirrone et al., 2010; Skov et al., 2004). GOM and PBM have much shorter atmospheric residence times and are deposited closer to their source locations (Lin et al., 2006; Pandey et al., 2011; Skov et al., 2007). Thus GEM is typically the dominant species of atmospheric Hg globally (Ebinghaus et al., 2002; Gustin and Jaffe, 2010; Pandey et al., 2011), and the only species subject to significant LRAT (Driscoll et al., 2013; Nguyen et al., 2009; Selin, 2009). The exact proportional make-up of TGM is dependent on proximity to $\mathrm{Hg}$ sources and the concentration of atmospheric oxidants (Selin et al., 2007; Skov et al., 2004; Sprovieri et al., 2010).

Ambient levels of the various forms of atmospheric $\mathrm{Hg}$ are most often measured using active or automated air samplers that draw a known volume of air over a $\mathrm{Hg}$ sorbent trap, which is desorbed periodically, and quantified (Lynam and Keeler, 2002). While commercially available active samplers are capable of measurements at relatively fine temporal resolution (Gustin and Jaffe, 2010), the spatial range of their application is limited to populated and generally affluent regions due to the high cost of the instruments, their energy requirements, and technical training necessary in their operation (Gustin and Jaffe, 2010; Gustin et al., 2011; Skov et al., 2007). Accordingly, the spatial resolution of atmospheric $\mathrm{Hg}$ measurements has been limited.

Our purpose is to comprehensively review the existing literature on passive air samplers (PASs) for atmospheric $\mathrm{Hg}$, focusing on GEM. Some of the samplers we review here are unable to distinguish between GOM and GEM (Gustin and Jaffe, 2010; Pandey et al., 2011; Skov et al., 2007). GEM generally makes up $>98-99 \%$ of TGM at most sampling locations (Pandey et al., 2011; Gustin and Jaffe, 2010; Gustin et al., 2011), and thus GOM is expected to contribute a relatively minor proportion to the overall uncertainty of a GEM measurement (Pandey et al., 2011). For the sake of simplicity, we will therefore refer to the sorbate as GEM in this review. Starting with a summary of the rationale for passive air sampling of GEM, we then discuss the basic elements of PASs. Features and specific requirements of effective PASs for GEM are discussed vis-à-vis existing designs. We conclude by outlining future perspectives in GEM passive air sampling research. This review differs from the recent review by Huang et al. (2014), which had a much wider scope and discussed man-made and naturally occurring (e.g. moss and lichen) PASs for $\mathrm{Hg}$, as well as wet and dry $\mathrm{Hg}$ deposition samplers. Furthermore, Huang et al. (2014) reviewed samplers for GEM, GOM, and PBM, whereas we focus this review on PASs for GEM only.

\section{The rationale for a passive air sampler for gaseous elemental mercury}

Mercury has been regulated by national agencies, international agreements, and most recently on a global scale through the United Nations Environmental Programme Minamata Convention (Driscoll et al., 2013; Pandey et al., 2011; Renner, 1999; UNEP, 2013). Under the Minamata Convention $\mathrm{Hg}$ mining is to be phased out, air emissions are to be controlled, and artisanal/small-scale gold mining is to be regulated (UNEP, 2013). Scientific evaluation of the effectiveness of control measures on mercury releases is stipulated under the convention and will require long-term monitoring at numerous sites around the world (UNEP, 2013).

While active air sampling works effectively when measuring GEM concentrations at sites with access to reliable electricity (Munthe et al., 2001; Schroeder et al., 1995), PASs provide an economical, zero-energy alternative for a number of specific sampling needs. The cost of passive sampling allows for a much larger number of samplers and therefore substantially increased spatial resolution, albeit at a coarser temporal resolution. Finer spatially resolved sampling would enable improved global examination of the efficacy of $\mathrm{Hg}$ regulations, as well as a basis from which to assess potential impacts of global climate change on long timescales. The accessibility of PASs is also critical for $\mathrm{Hg}$ monitoring and research in developing countries where the cost of active samplers might otherwise prohibit it. The potential for improved monitoring of $\mathrm{Hg}$ at remote sites, where the maintenance of active samplers would be difficult, is also intriguing since certain remote populations may be at elevated risk to $\mathrm{Hg}$ exposure. This is evident in aboriginal communities in Canada's north for example, where consumption of traditional foods with elevated concentrations of $\mathrm{MeHg}$, such as fish and marine mammals, places these communities at greater risk than non-aboriginal communities not subsisting on such diets (Govt. of Canada, 2012; Tian et al., 2011; Wheatley and Wheatley, 2000). This also extends to include $\mathrm{Hg}$ exposure (both MeHg in food and GEM in air) in communities in close proximity to small-scale artisanal gold mining activities (Barbosa et al., 2003; Sousa and Veiga, 2009).

Current atmospheric $\mathrm{Hg}$ models have a large and often unknown degree of uncertainty due in part to a lack of rigorous evaluation against real data (AMAP/UNEP, 2013; Keeler et al., 2009). Finer spatial monitoring could improve the accuracy of the modelling and future predictability of atmospheric $\mathrm{Hg}$ dispersion, transformation, and phase exchange processes that are fundamental to understanding the spa- 
tial and temporal variability of $\mathrm{Hg}$ in the global atmosphere (Keeler et al., 2009; Lin et al., 2006). The increased spatial resolution of data that is possible with PASs could also facilitate $\mathrm{Hg}$ source characterization. Mapping with high-spatialdensity sampler deployments would expedite the identification of both known and unknown $\mathrm{Hg}$ sources, as well as populations at greater exposure risk.

The small size and weight of certain PAS designs also facilitates their use in recording GEM concentrations in homes and workplaces or even in monitoring personal exposure to GEM. Mattoli et al. (2007) describe the importance of monitoring employee exposure in environments with elevated levels of GEM. Indeed personal PASs may help ensure working conditions comply with health and safety standards. Personal monitoring with PASs need not be limited to "at-risk" employees. Epidemiological $\mathrm{Hg}$ exposure characterization would likely benefit from personal $\mathrm{Hg}$ sampling within the general community across a wide range of $\mathrm{Hg}$ exposure scenarios.

In summary, there are different rationales for passive sampling of GEM. The most compelling rationales for a GEM PAS include

A measuring ambient GEM levels close to the global average over extended periods of time, possibly for longterm trend monitoring;

B measuring GEM concentration variability/gradients at fine spatial resolution close to point sources to the atmosphere;

C personal exposure monitoring for compliance and exposure assessment.

\section{Basic elements of passive air sampling}

Before discussing PASs for GEM specifically, there are underlying principles and important terminology in the chemistry and physics of passive sampling, regardless of the chemical of interest, that require introduction. PASs quantify the amount of a target compound that is taken up by the sorbent of the sampler from the atmosphere over a given period of time. Without electricity to pump air across the sorbent, PASs must rely on turbulent and/or molecular diffusion to deliver a target compound to the sorbent. To interpret the sorbed amount as a concentration of the target compound in air, a sampling rate (SR) specific to a particular sampler design and target compound must be known. SRs can be estimated theoretically but are usually determined by calibration using simultaneous measurements with reliable active sampling techniques (Gustin et al., 2011; Huang et al., 2012; Lyman et al., 2010; Mattoli et al., 2007; Skov et al., 2007; Zhang and Wong, 2007). Since considerable variability in sampling rates can result from turbulent airflow, PAS designs often include a diffusive barrier to assure that the rate- limiting step during uptake is via molecular diffusion over a fixed distance.

The SR $\left[\mathrm{L}^{3} \mathrm{~T}^{-1}\right]$ for a diffusive PAS, which quantifies the volume of air that is effectively stripped of target compound per unit of time, using Fick's first law, is governed by

$\mathrm{SR}=\frac{D A}{L}=\frac{m}{t C}$,

where $D$ is the molecular diffusion coefficient of the target compound in air $\left[\mathrm{L}^{2} \mathrm{~T}^{-1}\right] . L$ is the diffusive path length [L], which, in the case of a PAS with a porous diffusive barrier, needs to account for the tortuous path taken by a molecule diffusing through the barrier. $A$ is the surface area of the collection surface $\left[\mathrm{L}^{2}\right] ; m$ is the mass of sorbed compound $[\mathrm{M}]$; $t$ is the deployment time [T]; $C$ is the concentration of the compound in air $\left[\mathrm{ML}^{-3}\right]$. Once a SR for a particular compound and PAS has been determined, a concentration can be calculated from the mass of sorbed analyte by rearranging Eq. (1).

The uptake rate (UR) $\left[\mathrm{MT}^{-1}\right]$ in a diffusive sampler, which is the change in the mass of sorbed target compound over time, can also be calculated using Fick's first law:

$\mathrm{UR}=\frac{\mathrm{d} m}{\mathrm{~d} t}=D(T, P) A \frac{\mathrm{d} C}{\mathrm{~d} L}$,

where $\frac{\mathrm{d} C}{\mathrm{~d} L}$ is concentration gradient of the target compound in air across $L$. Note that whereas SR is independent of the analyte concentration $C$, UR is not.

During passive sampling, it is normally assumed that the SR is independent of the amount of sorbed analyte $m$. If the concentration $C$ in air is constant, this implies that $m$ is a linear function of deployment time $t$ (Fig. 1). As long as this assumption is valid, a sampler is said to operate in the linear uptake phase (Bohlin et al., 2007; Hayward et al., 2010). If deployment is too long, the SR will decline, either because the number of available sorption sites declines as the sorbent becomes saturated or because an equilibrium distribution between atmospheric gas phase and sorbent material is approached. During this curvilinear uptake phase, thermodynamic factors in addition to kinetic factors determine SR. If deployment continues, the sorbent eventually will either become saturated or reach its equilibrium uptake capacity, where no net uptake occurs and SR and UR become 0 . The length of the linear uptake period determines the maximum length of deployment (Fig. 1). In order to be able to use a PAS over extended deployment periods, the sorbent needs to have a large uptake capacity.

PASs can employ external shields to protect the sampler components from direct wind, sunlight, and precipitation and to reduce turbulent airflow. In many PASs, diffusive barriers further standardize the diffusive area and diffusive distance, thereby better controlling the SR, which in turn enables a more precise determination of concentration. The ideal diffusive barrier maximizes the rate of diffusion, and hence 


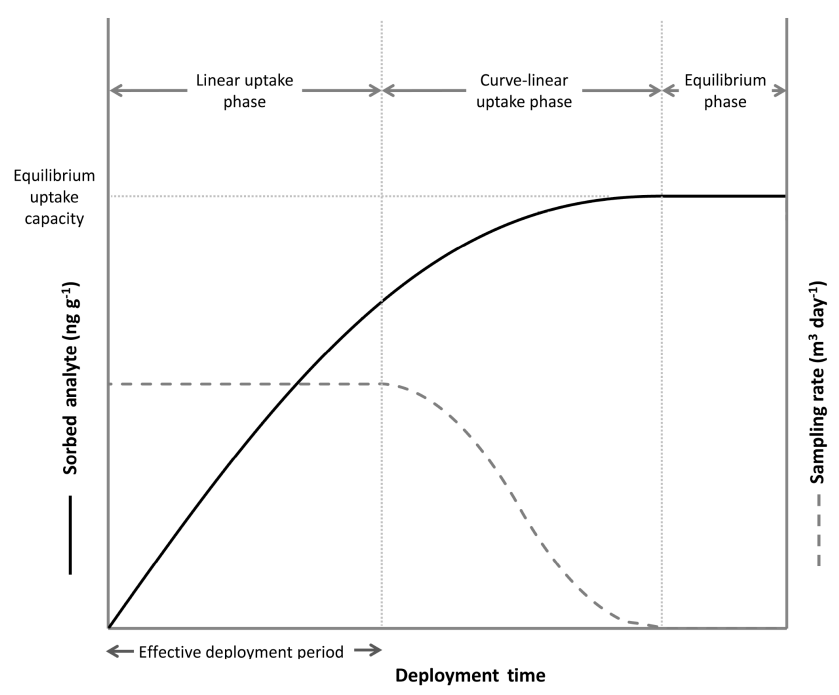

Figure 1. Curve characterizing the uptake of a compound in a generic PAS when the concentration of that compound in air is assumed to be constant. Initially the SR is constant and analyte uptake will be linear (or near linear) and the sampler can be described as being in the effective deployment period. As the sorbent becomes saturated or equilibrates with the atmospheric gas phase, the SR begins to decrease. Once the equilibrium uptake capacity of the sampler is reached the SR is 0 .

the SR, while minimizing both the impact of air turbulence (thereby increasing the precision of the SR) and the internal surface area (which could compete with the sorbent for analyte uptake). These goals are conflicting; strategies that can be used to increase the rate of diffusion, namely increasing the surface area across which diffusion occurs, shortening the diffusion distance, or using a diffusive barrier with high porosity, also increase the PAS's susceptibility to turbulence.

At one end of the spectrum of PAS are tube-type samplers, which have a small diffusive area, a long diffusive distance, but also a relatively low SR that is not very susceptible to turbulence (Brown et al., 2012; Król et al., 2010; James et al., 2012; Lyman et al., 2010). Uptake efficiency could be detrimentally affected in this design due to unintentional sorption of the target compound onto the relatively large internal surface area of the diffusion tube (Król et al., 2010). Using material inert to the target species may reduce this interference (Lyman et al., 2010). Box- or badge-type samplers maintain a similar axial diffusion mechanism but have shorter (or no) internal distances between the diffusive barrier and the sorbent material, which increases not only SR but also their susceptibility to turbulence. Radial samplers consist of a columnar sorbent surrounded by a cylindrical diffusive barrier. The purpose of this design is to increase the SR by maximizing the surface area across which diffusion occurs (Król et al., 2010). At the same time, it greatly decreases the ratio of sorbent surface area to internal housing surface area that could unintentionally sorb the target substance. The most prominent radial-type sampler is the commercially produced Radiello ${ }^{\circledR}$, which is the reference sampler housing for volatile organic compounds in Europe (Król et al., 2010).

There are also PAS designs without a porous diffusion barrier that do not seek to explicitly standardize the diffusion distance; the turbulent flow of air is allowed to pass freely over the sorbent (Shoeib and Harner, 2002; Xiao et al., 2007). Because SRs for such samplers are generally quite high, such designs are popular in PASs for semivolatile organic chemicals, the air concentrations of which are so low that high SRs are often required to sorb quantifiable amounts (Huang et al., 2012). The SR for such samplers is more susceptible to the influence of wind speed and even wind direction, causing substantially reduced accuracy and precision (Huang et al., 2012; May et al., 2011).

\section{Requirements of passive air samplers for gaseous elemental mercury}

\subsection{Low-level detection}

The most basic requirement is that a GEM PAS sorbs a sufficient amount of GEM for accurate and precise quantification. According to Eq. (1), the amount of GEM sorbed in a PAS increases linearly with the air concentration $C$, the $\mathrm{SR}$, and the deployment time $t$. The requirement to keep the SR tightly controlled (see Sect. 4.2) implies that the SR has an upper limit. The length of deployment is limited by both the desired temporal resolution and the equilibrium uptake capacity, i.e. the need to remain in the linear uptake phase (Fig. 1). At a site with an average GEM concentration of $2 \mathrm{ng} \mathrm{m}^{-3}$ a sampler with a low SR of $0.001 \mathrm{~m}^{3}$ day $^{-1}$ (typical of a tube-type sampler) deployed for 1 day, 1 week, 1 month, or 1 year would sorb $0.002,0.014,0.06$, and $0.73 \mathrm{ng}$ of $\mathrm{Hg}$. However, a sampler with a high SR of $1 \mathrm{~m}^{3}$ day $^{-1}$ (typical of a sampler without a diffusive barrier) would collect 2, 14, 60, and $730 \mathrm{ng}$ during the same time periods. Whether a sorbed amount is sufficient for reliable quantification depends to a large extent on the method detection limit (MDL) of the analytical technique. A sampler designed to measure GEM in contaminated environments (rationales B and C) will not require the low MDLs needed for a PAS that aims to measure background atmospheric GEM concentrations (rationale A).

\subsection{Tightly controlled sampling rates}

The European Union has stipulated that a maximum uncertainty of $50 \%$ for measurement of GEM concentration is acceptable (European Commission, 2005). However, such a general standard of uncertainty is unlikely to be appropriate for all monitoring needs. Ambient background concentrations of GEM typically vary by less than $0.5 \mathrm{ng} \mathrm{m}^{-3}$ (approximately $<25 \%$ of the average concentration; Gustin et al., 2011; Kellerhals et al., 2003; Kock et al., 2005; Lyman and Gustin, 2008). If the sampler application requires the 

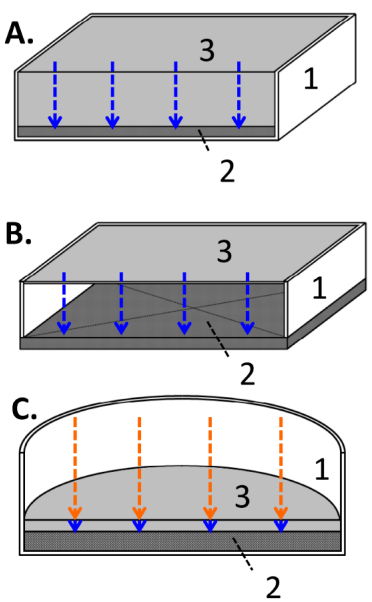

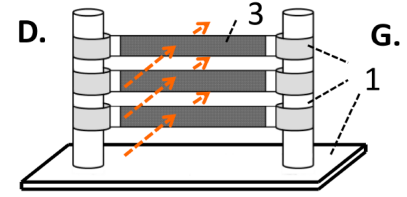

E.

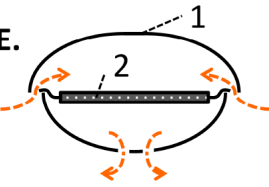

F.

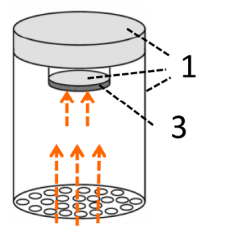

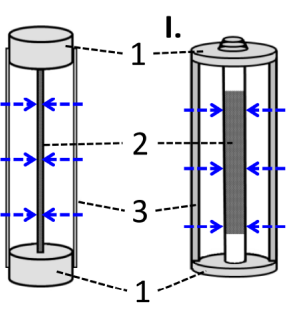

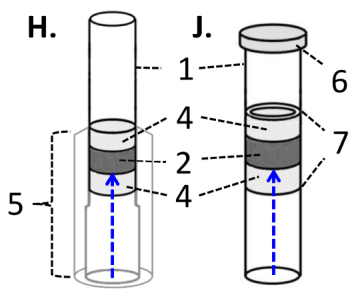

Legend:

1. Non-diffusive sampler housing

2. Sorbent material

3. Diffusive barrier

4. Quartz wool

5. Teflon $^{\circledR}$ diffusor tube (variable length)

6. End Cap (non-diffusive)

7. Crimp in quartz tube

Transport by

predominantly turbulent airflow Transport by

i predominantly diffusive airflow

Figure 2. Schematics of existing PASs for GEM. Sampler A: box-type axial-diffusion-type PAS tested by McCammon and Woodfin (1977). Sampler B: box-type axial-diffusion-type PAS by Mattoli et al. (2007). Sampler C: badge-type axial-diffusion-type PAS by Mniszek (2001). Sampler D: PAS by Brumbaugh et al. (2000) containing liquid sorbent inside lay-flat low-density polyethylene tubing. Sampler E: two-bowltype PAS by Huang et al. (2012). Sampler F: modified axial PAS by Zhang et al. (2012). Sampler G: radial diffusion PAS by Gustin et al. (2011). Sampler H: tube-type PAS by Nishikawa et al. (1999). Sampler I: radial diffusion PAS by Skov et al. (2007). Sampler J: tube-type PAS by Brown et al. (2012). Sampler images are not to scale and slight variances may exist from actual designs.

ability to discriminate such variability (rationale A), Gustin et al. (2011) estimated that PASs need to be able to resolve GEM concentration differences of $0.1 \mathrm{ng} \mathrm{m}^{-3}$. This implies that very high precision and accuracy of the measurement are essential. In particular, meteorological factors that may vary between sampling sites (such as temperature, relative humidity, and wind speed) cannot be allowed to have a strong effect on the SR. Otherwise, it will be impossible to attribute small differences in the amounts sorbed in different samplers to differences in air concentrations. Such high precision and accuracy in the SR of a PAS can probably only be achieved by tightly controlling the diffusive distance through the use of a diffusive barrier. Because tightly controlling the SR inevitably means a lower SR, such PASs require more sensitive analytical techniques and/or longer deployment times (see Sect. 4.1). GEM concentrations in and around point sources are not only higher than at background sites, but they can also vary by multiple orders of magnitude (Carpi and Chen, 2001; Liu et al., 2009; Malm et al., 1995). If the primary mandate of a PAS is the characterization of such concentration variability close to sources (rationales B and C), the accuracy and precision of the PAS's SR need not be as high as for PASs recording background levels, where variability is low. Precision and accuracy, of course, depend not only on a tightly controlled SR but also on the precision and accuracy of the analytical method for determining $\mathrm{Hg}$ concentrations in the sorbent.

\subsection{High and stable equilibrium uptake capacity}

An important feature of PASs is their ability to provide timeaveraged concentrations over extended time periods. In many deployment scenarios, especially in remote regions and in developing countries, travel to and from the sampling sites is associated with considerable time, effort, and cost, which limits the number of site visits. In such cases, deployment times that extend over months or even years are desirable. Long deployments demand sorbents that not only have a very high uptake capacity but also can retain this capacity for a long time. While it is possible to envisage scenarios involving deployments of a week or less (especially for rationales B and C), a low-capacity sampler will inevitably be limited in its applicability, especially if its capacity may be subject to variability (e.g. as a result of meteorological factors or ageing processes). A high-capacity sampler can still serve in short deployments as long as it sorbs reliably quantifiable amounts.

\subsection{Simple and inexpensive sampler and analysis}

A good design should be simple to produce and be made from inexpensive materials. The samplers should be easily and quickly deployed and retrieved. The analysis should be straightforward. Ideally, exposed samplers should be easily stored (even for extended time periods) and transported.

\subsection{Method validation}

To find wide acceptance, a PAS's performance must also be well validated against other broadly accepted methods, usu- 
Table 1. Performance of PASs for GEM from published studies. Variability associated with environmental factors was not included as the majority of studies lacked this information.

\begin{tabular}{|c|c|c|c|c|c|c|c|c|c|}
\hline Author(s) & $\begin{array}{l}\text { PAS type and } \\
\text { dimensions } \\
\left(A: \mathrm{cm}^{2} ; \quad d:\right. \\
\mathrm{cm})\end{array}$ & Diffusive barrier & Sorbent material & Analytical method & $\begin{array}{l}\text { Sampling rate } \\
\left(\mathrm{m}^{3} \text { day }^{-1}\right)\end{array}$ & $\begin{array}{l}\text { Observed } \\
\text { concentration } \\
\left(\mathrm{ng} \mathrm{m}^{-3}\right)\end{array}$ & $\begin{array}{l}\text { MDL, DT for } \\
\text { MDL } \\
\left(\mathrm{ng} \mathrm{m}^{-3} \mathrm{day}^{-1}\right)\end{array}$ & $\begin{array}{l}\text { DT tested } \\
\text { (days) }\end{array}$ & Uncertainty (\%) \\
\hline $\begin{array}{l}\text { McCammon and } \\
\text { Woodfin (1977) }\end{array}$ & $\begin{array}{l}\text { Axial }- \text { box } \\
(A: \sim 750 \\
d: \text { N/A })\end{array}$ & $\begin{array}{l}\text { Diffusive film of un- } \\
\text { known thickness and } \\
\text { composition on top of } \\
\text { sorbent }\end{array}$ & Gold foil & Not reported & Not reported & $\begin{array}{l}\sim 25000- \\
300000\end{array}$ & Not reported & 0.33 & $\begin{array}{l}8 \pm 7 \text { (accuracy to ac- } \\
\text { tive conc.) }\end{array}$ \\
\hline $\begin{array}{l}\text { Mattoli et } \\
\text { al. (2007) }\end{array}$ & $\begin{array}{l}\text { Axial - box } \\
(A: 400 \\
d 1.5)\end{array}$ & $\begin{array}{l}\text { Cotton paper and glass- } \\
\text { based filters of different } \\
\text { porosity }\end{array}$ & Gold film & $\begin{array}{l}\text { Electric sensor measur- } \\
\text { ing change in resistance } \\
\text { upon } \mathrm{Hg} \text { sorption to gold }\end{array}$ & Not reported & 16000 & $1000,0.07$ & real-time & Not reported \\
\hline $\begin{array}{l}\text { Nishikawa et } \\
\text { al. (1999) }\end{array}$ & $\begin{array}{l}\text { Axial - tube } \\
(A: 28.3, \\
78.5,133 ; \\
d: 3,10,30)\end{array}$ & No & $\begin{array}{l}\text { Gold-coated } \\
\text { Chromosorb }\end{array}$ & $\begin{array}{l}\text { Thermal desorption and } \\
\text { CVAAS }\end{array}$ & $0.0031 \pm 0.0017^{b}$ & $1.2-4400$ & Not reported & $11-126$ & $\begin{array}{l}30 \pm 35 \text { (accuracy to } \\
\text { active conc.) }\end{array}$ \\
\hline $\begin{array}{l}\text { Mniszek (2001); } \\
\text { Prokopowicz } \\
\text { and Mniszek } \\
(2005)\end{array}$ & $\begin{array}{l}\text { Axial - badge } \\
(A: 530 ; d: 5)\end{array}$ & $\begin{array}{l}\text { Permeable tissue placed } \\
\text { on top of sorbent }\end{array}$ & Hopcalite & $\begin{array}{l}\text { Solvent extraction and } \\
\text { CVAAS }\end{array}$ & $0.045 \pm 0.004$ & 220-13900 & $220,0.25$ & 0.25 & Not reported \\
\hline $\begin{array}{l}\text { Brown et } \\
\text { al. (2012) }\end{array}$ & $\begin{array}{l}\text { Axial - tube } \\
(A: 23.8 \\
d: 57)\end{array}$ & No & Gold-coated silica & $\begin{array}{l}\text { Thermal desorption and } \\
\text { CVAFS }\end{array}$ & 0.00031 & $2.2-15$ & $\sim 0.44,74$ & $74-93$ & $\begin{array}{l}30 \text { (full expanded un- } \\
\text { certainty) }\end{array}$ \\
\hline $\begin{array}{l}\text { Skov et } \\
\text { al. (2007) }\end{array}$ & $\begin{array}{l}\text { Radial } \\
(A: 480 \\
d: 5.4)\end{array}$ & $\begin{array}{l}\text { Porous HDPE } \\
\left(\text { Radiello }^{\circledR}\right)\end{array}$ & Solid gold & $\begin{array}{l}\text { Thermal desorption and } \\
\text { CVAFS }\end{array}$ & $0.0805 \pm 0.0062$ & $1.8-14.2$ & $0.05,3$ & $1-3$ & $\begin{array}{l}7.7 \text { (replicate preci- } \\
\text { sion only) }\end{array}$ \\
\hline $\begin{array}{l}\text { Gustin et } \\
\text { al. (2011) }\end{array}$ & $\begin{array}{l}\text { Radial } \\
(A: \\
\mathrm{Au} \quad \text { plate: } \\
310 ; \\
\mathrm{Ag} \quad \text { wire: } \\
377 ; d: \sim 4)\end{array}$ & $\begin{array}{l}\text { Porous HDPE } \\
\text { (Radiello }{ }^{\circledR} \text { and own de- } \\
\text { sign) }\end{array}$ & $\begin{array}{l}\text { Gold sputter-coated } \\
\text { quartz plates and sil- } \\
\text { ver wire }\end{array}$ & $\begin{array}{l}\text { Thermal desorption and } \\
\text { CVAFS }\end{array}$ & $\begin{array}{l}0.073 \pm 0.032 \\
\text { (field) } \\
0.125 \text { (chamber) }\end{array}$ & $1.2-2.9$ & Not reported & 7 & Not reported \\
\hline $\begin{array}{l}\text { Zhang et } \\
\text { al. (2012); Guo } \\
\text { et al. (2014) }\end{array}$ & $\begin{array}{l}\text { Axial modi- } \\
\text { fied } \\
\text { (A: } \sim 700 ; d: \\
100)\end{array}$ & No & $\begin{array}{l}\text { Sulfur-impregnated } \\
\text { activated carbon }\end{array}$ & $\begin{array}{l}\text { thermal decomposition, } \\
\text { amalgamation and AAS }\end{array}$ & $\begin{array}{l}0.13 \pm 0.03 \text { (wind } \\
\text { speed dependent) }\end{array}$ & $1.4-6.4$ & $0.08,30$ & $10-40$ & $\begin{array}{l}12 \pm 6 \text { (replicate pre- } \\
\text { cision only); } \\
22 \pm 15^{\mathrm{a}, \mathrm{b}} \text { (accuracy } \\
\text { to active conc.) }\end{array}$ \\
\hline $\begin{array}{l}\text { Brumbaugh et } \\
\text { al. (2000) }\end{array}$ & $\begin{array}{l}\text { Liquid-filled } \\
\text { tube (A: } \\
7600 ; d: \sim 0)\end{array}$ & $\begin{array}{l}\text { Porous LDPE membrane } \\
\text { thickness not specified }\end{array}$ & $\begin{array}{l}\text { Gold chloride, nitric } \\
\text { acid solution }\end{array}$ & $\begin{array}{l}\text { Flow injection CVAAS } \\
\text { or ICP-MS }\end{array}$ & $\begin{array}{l}0.002 \text { (temperature } \\
\text { dependent) }\end{array}$ & 25 & $2.0,28$ & $28-84$ & $\begin{array}{l}5-10 \text { (replicate preci- } \\
\text { sion only) }\end{array}$ \\
\hline $\begin{array}{l}\text { Huang et } \\
\text { al. (2012) }\end{array}$ & $\begin{array}{l}\text { Two bowl ( } A \text { : } \\
1735)\end{array}$ & No & $\begin{array}{l}\text { Gold-coated quartz fi- } \\
\text { bre filters }\end{array}$ & $\begin{array}{l}\text { Thermal desorption and } \\
\text { CVAFS }\end{array}$ & $\begin{array}{l}6.6 \pm 1.4 \text { (wind } \\
\text { speed dependent) }\end{array}$ & $1.9 \pm 0.4$ & $0.02,14$ & $0.33-5$ & $\begin{array}{l}19 \pm 14 \text { (accuracy to } \\
\text { active conc.) }\end{array}$ \\
\hline
\end{tabular}

ally active air monitoring systems with satisfactory precision and accuracy (Ebinghaus et al., 1999; Munthe et al., 2001; Schroeder et al., 1995).

\section{Existing passive air samplers for gaseous elemental mercury}

Passive sampling of GEM in air has been documented in the literature for over 35 years (McCammon and Woodfin, 1977). Over the years, 10 different PASs for GEM have been proposed (Fig. 2); their main characteristics are summarized in Table 1. Several of the proposed designs are classical axialdiffusion-type dosimeters, including the tube-type sampler by Nishikawa et al. (1999; Fig. 2H), badge-type PAS by Mniszek (2001; Fig. 2C), and the personal box-type dosimeter by Mattoli et al. (2007; Fig. 2B). The design by Brown et al. (2012; Fig. 2J), which relies on commercial tubes normally used in active air sampling, and by Zhang et al. (2012; Fig. 2F), which involves a slightly larger diffusion tube, also constitute axial diffusion samplers. Of these five axial diffusion samplers, only Mattoli et al. (2007; Fig. 2B) propose the use of a diffusive barrier - in the form of "cotton paper and glass-based filters of different porosity" - to dampen the influence of variable face velocity on uptake. While the design by Mniszek (2001) involves a permeable tissue, it is placed directly on top of the sorbent and not in the entrance to the diffusion tube and thus does not serve to reduce air turbulence in the diffusion tube. The designs by Skov et al. (2007; Fig. 2I) and Gustin et al. (2011; Fig. 2G) are radial-diffusiontype samplers using either a commercial Radiello ${ }^{\circledR}$ diffusive barrier (Skov et al., 2007; Gustin et al., 2011) or one made from expanded polytetrafluoroethylene (PTFE; Gustin et al., 2011; Peterson et al., 2012). The sampler design by Huang et al. (2012; Fig. 2E), which has been adapted from a sampler for semivolatile organic compounds and involves the sorbent placed in the space between two bowls, makes no attempt to have the SR limited by a molecular diffusion step.

In two of the samplers, diffusion through a barrier (rather than through air) is meant to be the rate-limiting step to GEM uptake in the sorbent. In the PAS developed by the 3M Company and tested by McCammon and Woodfin (1977; Fig. 2A), GEM diffuses through a barrier film to a gold foil. Using experiments with a range of face velocities, it was confirmed that uptake in the sampler was not affected by air turbulence (McCammon and Woodfin, 1977); thus diffusion through the barrier was indeed the rate-limiting step. In the liquid sorbent sampler by Brumbaugh et al. (2000; Fig. 2D), it is assumed that diffusion through a low-density polyethylene (LDPE) lay-flat tube membrane is the rate-limiting step; i.e. it is slower than diffusion through the air boundary layer surrounding the membrane and slower than oxidation within 
the liquid sorbent. No experiments were conducted to validate this.

\section{Do existing samplers meet the identified requirements?}

\subsection{Do existing gaseous elemental mercury passive air samplers sorb amounts above detection limits?}

While the lowest GEM concentration that can be determined with a PAS depends on its SR and the deployment time, the MDL of the analytical technique is an important consideration. Most of the existing PASs for GEM rely on spectroscopic techniques for analysis. Four studies relied on thermal desorption followed by cold vapour atomic fluorescence spectrometry (CVAFS) to quantify the amount of GEM sorbed on a gold-based sorbent (Brown et al., 2012; Gustin et al., 2011; Huang et al., 2012; Skov et al., 2007), or a silver wire (Gustin et al., 2011). Four studies used atomic absorption spectroscopy (AAS): Mniszek (2001) first dissolved Hg from a hopcalite sorbent using nitric acid prior to analysis by AAS; Zhang et al. (2012) analysed the mercury sorbed to carbon using an automated analyser that relies on thermal decomposition and amalgamation, followed by AAS; Brumbaugh et al. (2000) directly analysed the gold chloride solution by AAS or inductively coupled plasma-mass spectrometry (ICP-MS); Nishikawa et al. (1999) utilized cold vapour atomic absorption spectroscopy (CVAAS) to analyse their gold sorbent.

While the MDL of spectroscopic techniques should generally be low enough for a GEM PAS to be capable of measuring ambient background levels, for three PASs this is questionable. The solvent extraction step required for the PAS by Mniszek (2001) results in a high MDL that limits its deployment to indoor settings with elevated $\mathrm{Hg}$ concentrations, e.g. at workplaces of elevated $\mathrm{Hg}$ concentrations. The long diffusive distance of the tube-type sampler by Brown et al. (2012) yields a very low $\mathrm{SR}\left(3.1 \times 10^{-4} \mathrm{~m}^{3}\right.$ day $\left.^{-1}\right)$, demanding very long deployment periods (year-long deployments are recommended for typical background GEM concentrations of 1$2 \mathrm{ng} \mathrm{m}^{-3}$ ) to sorb quantifiable amounts (Table 1). The MDL of the PAS by Brumbaugh et al. (2000) was $2 \mathrm{ng} \mathrm{m}^{-3}$ over a 4-week deployment, a value slightly above global atmospheric averages, and thus has limited applicability in monitoring background concentrations.

PASs relying on non-spectroscopic techniques are clearly unsuitable for monitoring GEM at ambient levels. While the method used in the analysis of the sampler tested by McCammon and Woodfin (1977) is not revealed, it has a very high MDL (Table 1) that renders it impractical for deployment in all but the most contaminated environments. The sampler design by Mattoli et al. (2007) also has a high MDL (Table 1) due to the use of electronic resistivity for analysis. Nonetheless, PASs that effectively quantify higher concentrations are not necessarily rendered obsolete by designs that can adequately monitor GEM at lower concentrations. The equilibrium uptake capacity of samplers targeting trace concentrations of GEM may be too low for use in high-concentration environments, potentially leading to an underestimation of actual concentrations.

\subsection{Do existing gaseous elemental mercury passive air samplers have tightly controlled sampling rates?}

The SRs of existing PASs for GEM range over 4 orders of magnitude (Table 1). The lowest SR of $0.0003 \mathrm{~m}^{3} \mathrm{day}^{-1}$ was observed for the sampling tubes by Brown et al. (2012) which combine a relatively large diffusive distance $(>50 \mathrm{~mm})$ with a relatively small diffusive area $\left(<25 \mathrm{~mm}^{2}\right)$. On the other extreme is the double-bowl design by Huang et al. (2012) which has a SR of $>5 \mathrm{~m}^{3} \mathrm{day}^{-1}$, because GEM uptake does not occur solely by molecular diffusion. The remainder of the samplers tend fall within a range of approximately $0.003 \mathrm{~m}^{3}$ day $^{-1}$ for the tube-type sampler by Nishikawa et al. (1999) to $0.13 \mathrm{~m}^{3} \mathrm{day}^{-1}$ for the modified axial sampler by Zhang et al. (2012).

Several studies have conducted controlled chamber experiments to test to what extent the SR of a PAS is influenced by meteorological conditions and other factors. Changing temperature has the two-fold effect of shifting partition equilibria for GEM between the sorbent and air and altering the rate of GEM diffusion, both potentially affecting SRs. Four studies have looked at the impact of temperature on uptake. The diffusion both through the barrier film in the 3M sampler (McCammon and Woodfin, 1977) and through the LDPE membrane of the sampler by Brumbaugh et al. (2000) was found to be dependent on temperature. McCammon and Woodfin (1977) noted a $1.61 \%$ increase in the rate of uptake per ${ }^{\circ} \mathrm{C}$. The SR of the sampler by Brumbaugh et al. (2000) varied by a factor of 4 within the range -11 to $40^{\circ} \mathrm{C}$, likely a result of the dependence on temperature of the permeability of the LDPE membrane (Levy et al., 2009). Also in samplers where the rate-limiting step is diffusion through air, temperature has the potential to affect the SR through its influence on the diffusion coefficient of $\mathrm{Hg}$ in air (Eq. 2). However, the effect is quite small and neither Skov et al. (2007) nor Guo et al. (2014) observed a temperature dependence of the SR when testing at 6,27 , and $36.5^{\circ} \mathrm{C}$ and $-10,0,15,25$, and $35^{\circ} \mathrm{C}$ respectively.

The effect of variable wind speeds on SRs is likely the principal concern in outdoor passive air sampling. Diffusive samplers assume the presence of a laminar layer of stagnant air surrounding the sorbent, with the rate-limiting step for analyte uptake in most samplers being diffusion through this layer (Shoeib and Harner, 2002). Wind has the effect of increasing SRs by decreasing the thickness of the stagnant air layer, essentially reducing the diffusive path length and in turn leading to increased and/or more variable SRs (Bartkow et al., 2005; Moeckel et al., 2009; Pennequin-Cardinal et al., 

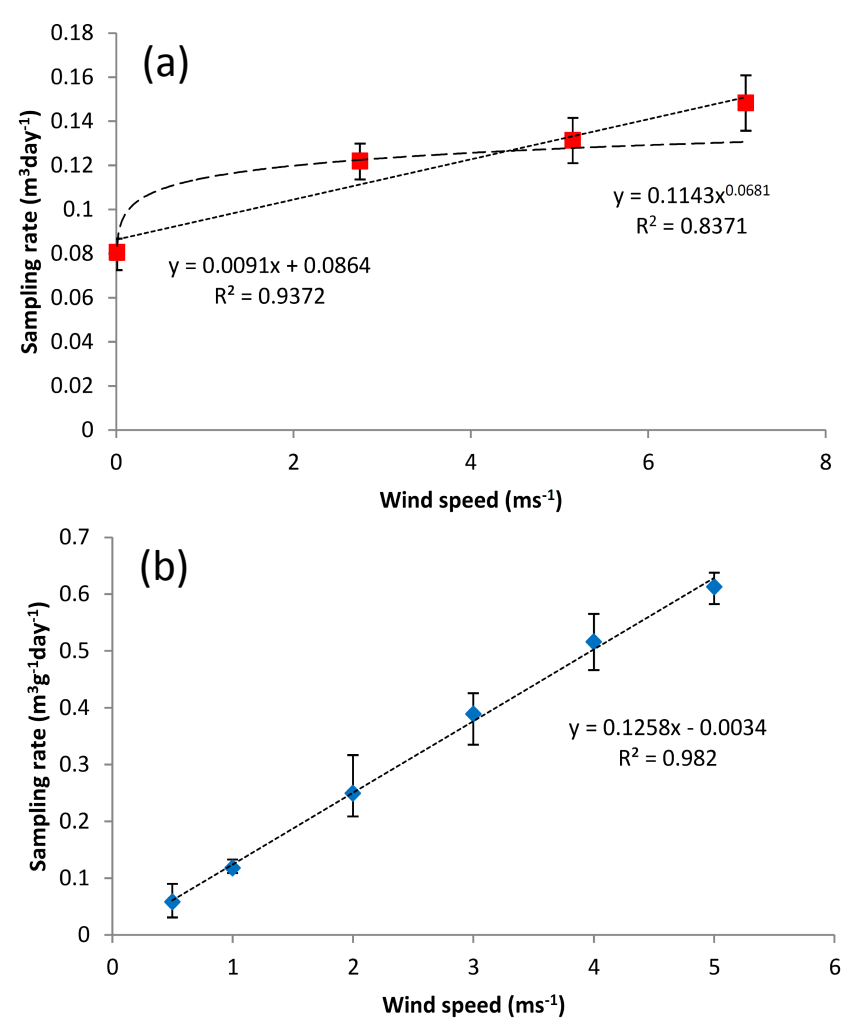

Figure 3. Wind speed dependence of SRs for GEM PASs. (a) Data from Skov et al. (2007); values are the average of 18 replicates. (b) Data from Guo et al. (2014); values are the average of five replicates. Data from (b) were obtained using PlotDigitizer, Free Software, v2.6.6.

2005; Plaisance et al., 2002; Zhang et al., 2012). Four studies exposed their samplers to controlled GEM concentration at different wind speeds, again with divergent results. McCammon and Woodfin (1977) noted no dependence of GEM uptake on face velocities, which were $0.3,0.5$, and $1.3 \mathrm{~m} \mathrm{~s}^{-1}$. In this sampler, uptake is limited not by diffusion through an air boundary layer but by diffusion through a diffusive barrier. Brown et al. (2012) also found no dependence of the SR on the flow rate through the exposure chamber (range of wind speeds tested was not given), presumably because of the very small and long diffusion tube. However, Skov et al. (2007) measuring at wind speeds of $0.002,2.75,5.15$, and $7.1 \mathrm{~m} \mathrm{~s}^{-1}$, noted an almost doubling of the SR between windstill conditions and the highest wind speed (Fig. 3a). The dependence of SR on wind speed was described as non-linear, with greater effects observed at low wind speeds (Fig. 3a; Skov et al., 2007). The wind speed effect on GEM uptake in this sampler is similar to what has been observed for the uptake of benzene also using a Radiello ${ }^{\circledR}$-based diffusive barrier (Pennequin-Cardinal et al., 2005; Plaisance et al., 2002). However, Skov et al. (2007) did not test wind speeds between 0.002 and $2.75 \mathrm{~m} \mathrm{~s}^{-1}$ (region of greatest effect on $\mathrm{SR}$ ), and adding a linear trend line improved the relation- ship from the power trend line that was originally fitted to the data (Fig. 3a). Guo et al. (2014) tested their sampler at wind speeds of $0.5,1,2,3,4$, and $5 \mathrm{~m} \mathrm{~s}^{-1}$ and observed a linear relationship between SR and wind speed, which led to a more than 6-fold increase in SR between 0.5 and $5 \mathrm{~m} \mathrm{~s}^{-1}$ (Fig. 3b). Even the application of a wind-speed-dependent SR model could not entirely account for the effect of wind speed on SR (Guo et al., 2014). Although Huang et al. (2012) did not explicitly test the wind speed dependence of GEM uptake, the sampler design that they employed is strongly influenced by both wind speed and angle of incidence (Huang et al., 2012; May et al., 2011).

Mattoli et al. (2007) reported that increasing relative humidity from 50 to $100 \%$ increased GEM uptake on a gold surface by approximately $15 \%$, which may be caused by the resistivity-based analytical technique used by the dosimeter. Skov et al. (2007) did not observe a significant effect of relative humidity in laboratory testing of synthetic air (presumably low relative humidity) and high-relative-humidity air (approximately $90 \%$ relative humidity) using a gold sorbent. Similarly, Guo at al. (2014) observed no dependence of GEM uptake to their activated carbon-based PAS across a relative humidity range from 25 to $90 \%$.

If uptake in a PAS has been measured simultaneously with active monitoring system measurements (Gustin et al., 2011; Huang et al., 2012; Nishikawa et al., 1999; Zhang et al., 2012), it is possible to test whether the SR of a PAS is constant under field conditions. We can plot the UR (amount of GEM sorbed per day) observed in the fielddeployed samplers against the GEM concentration during the deployment period (Fig. 4; Gustin et al., 2011; Huang et al., 2012; Nishikawa et al., 1999). Ideally, such a plot should go through the origin (suggesting no uptake if no GEM is present) and be linear, suggesting that (i) the SR is not a function of GEM concentration and (ii) that the sampler operated in the linear uptake phase during all deployments. The plots of UR versus concentration in Gustin et al. (2011; Fig. 4a), Huang et al. (2012; Fig. 4b), and Nishikawa et al. (1999; Fig. 4c) show fairly broad scatter and only weakly or indistinguishable linear relationships. Field testing of silver wire sorbents (Gustin et al., 2011; data not available in the paper) also showed no relationship. The scatter of the data for the activated-carbon-based PAS by Zhang et al. (2012; blue diamond data series Fig. 4d) was less, especially in the initial field testing. However, active measurements only covered $\sim 11 \%$ of the sampling period, which could bias the comparison if GEM levels fluctuated strongly. Subsequent testing of the PAS by Guo et al. (2014; yellow triangle and red square data series Fig. 3d) revealed a significant effect of wind speed on SR, which weakened the linear relationship between UR and actively measured GEM concentration. The data in Table 1 and Fig. 4 reveal that these PASs do not have the level of accuracy and precision that Gustin et al. (2011) suggested is necessary for measuring GEM at background levels. 

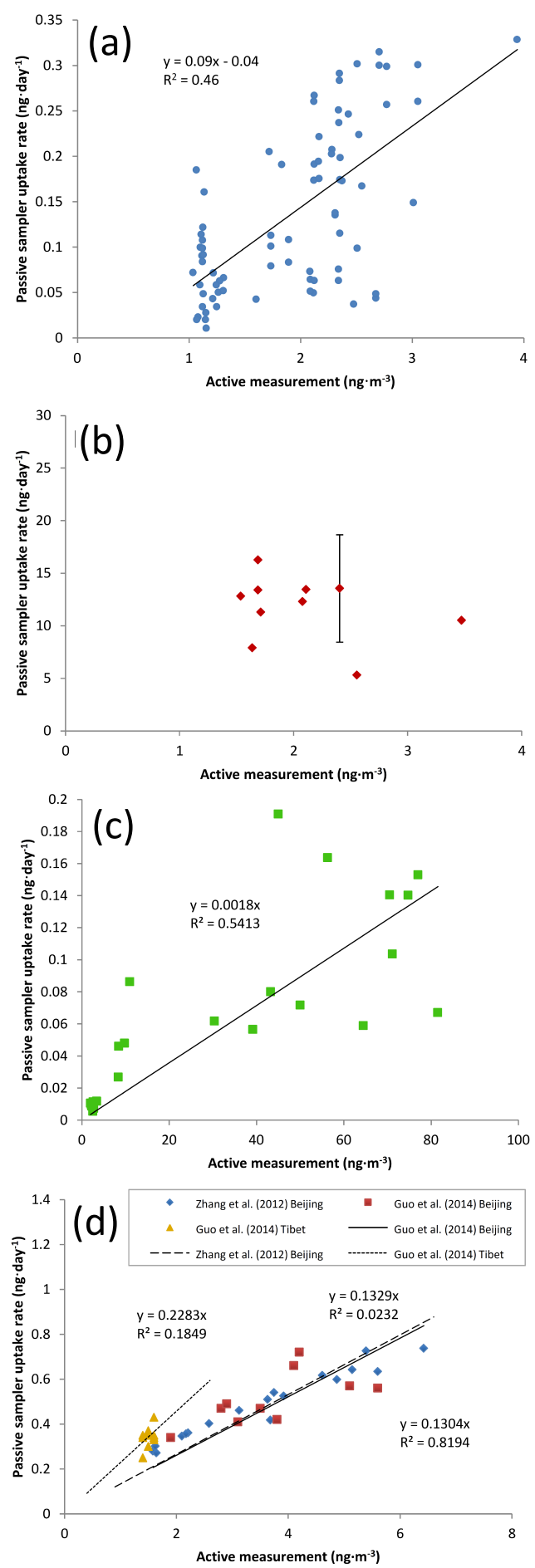

Figure 4. Passive sampler uptake rate (UR) plotted against the corresponding mean actively measured GEM concentration. (a) Data for gold plate sorbents from Gustin et al. (2011); trend line was not forced through 0 by authors. (b) Data from Huang et al. (2012). (c) Data from Nishikawa et al. (1999); data above $100 \mathrm{ng} \mathrm{m}^{-3}$ were excluded to enable a focus on the PAS's performance at relevant ambient GEM concentrations (for full log-log scaled graph see original paper). (d) Data from Zhang et al. (2012) and Guo et al. (2014) for the same PAS design. Data from panels $(\mathbf{a}, \mathbf{b}, \mathbf{c})$ were obtained using PlotDigitizer, Free Software, v2.6.6.
Additionally Brown et al. (2012), Brumbaugh et al. (2000), and Mniszek (2001) field tested the SR of their samplers outdoors. However, data were not reported in the format shown in Fig. 4. The precision of the PAS by Brown et al. (2012) compared to actively measured values was low (although active measurements were only determined on a weekly basis and may not give an accurate estimation of mean concentrations during the deployment period). Overall uncertainty of these results was determined to be $\sim 30 \%$ (Brown et al., 2012). Part of this uncertainty was attributed to the low SR of the design, which despite the length of deployments resulted in a very low amount of GEM being sorbed by the PAS (Brown et al., 2012). Brumbaugh et al. (2000) did not take any actively measured GEM samples along with the passive measurements, and hence no assessment of calibrated SR accuracy could be made (Brumbaugh et al., 2000). Mniszek (2001) assessed the effectiveness of their axial badge PAS in high-concentration workplace scenarios in the Polish chloralkali industry. On average the relative percent difference of passive measurements from active measurements was high at $173 \pm 177 \%$ (Mniszek, 2001). However, the active measurements were taken by pumping air across the same hopcalite sorbent used in the PAS and it was itself still being developed. Prokopowicz and Mniszek (2005) then tested the same passive and active sampling setups in seven hospitals and one residence across Poland that also had elevated GEM. Here, results were much closer, with the relative percent difference of passive measurements from active measurements being $16.2 \pm 15.1 \%$ (Prokopowicz and Mniszek, 2005). The higher limits of detection for the sampling method used meant the PAS could not be used for deployments at background concentrations of GEM.

\subsection{Do the sorbents used in existing samplers have a sufficiently high and stable uptake capacity?}

Among the 10 samplers reviewed here, all but 1 have relied on metals as sorbents: either gold, silver, or hopcalite, an alloy of manganese and copper. Gold-based sorbents are especially popular, having found use in eight of the samplers. This preference for gold is due to its high affinity to $\mathrm{Hg}$ (Greaves et al., 1997; Gustin et al., 2011; Rex et al., 2006), and presumably also due to its common and successful use in active air monitoring of GEM. Gold has been deployed as a film (Mattoli et al., 2007), foil (McCammon and Woodfin, 1977), and solid cylinder (Skov et al., 2007), but it is most often used as a thin coating on a carrier material, partly to increase the surface area to volume ratio of the sorbent and partly to reduce the amount of gold required and therefore the cost. Examples are sputter-coated quartz plates (Gustin et al., 2011; Peterson et al., 2012), quartz fibre filters (Huang et al., 2012; May et al., 2011), gold-coated silica (Brown et al., 2012), and Chromosorb (Nishikawa et al., 1999). The sampler design by Brumbaugh et al. (2000) used a liquid sorbent, specifically a gold chloride/nitric acid solution, which is filled and sealed 

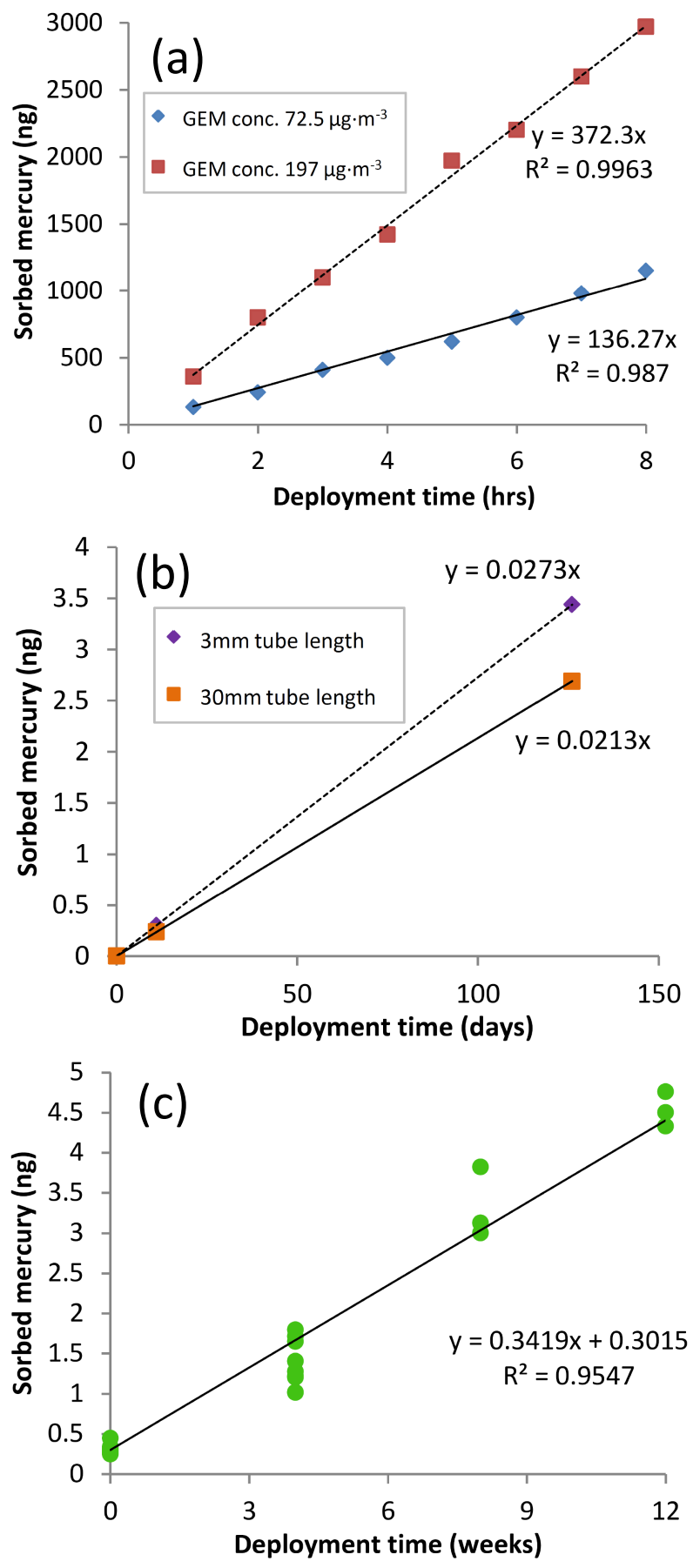

Figure 5. Passive sampling uptake curves plotting deployment time against the mass of sampled Hg. (a) Data from Mniszek et al. (2001). (b) Data from Nishikawa et al. (1999); each data point represents the mean of five replicates. (c) Data from Brumbaugh et al. (2000); $y$ intercept represents the mean $\mathrm{Hg}$ level of sorbent blanks. Graph (a) and graph (b) data were obtained using PlotDigitizer, Free Software, v2.6.6. into a LDPE membrane pouch. One PAS utilized silver in the form of a solid wire (Gustin et al., 2011), while another used a sulfur-impregnated activated carbon sorbent (Zhang et al., 2012). Activated carbon has a large surface area to volume ratio, which results in a high number of sites available for interaction with GEM (Karatza et al., 1996, 2000; Lee et al., 2006; Vidic et al., 1998). Sulfur-impregnated activated carbon in particular may have considerable potential for uptake of GEM due to the affinity of $\mathrm{Hg}$ to sulfur (Suresh Kumar Reddy et al., 2013; Vidic et al., 1998; Vidic and McLaughlin, 1996; Vidic and Siler, 2001; Zhang et al., 2012).

The uptake capacity for GEM has not been directly measured for any of these sorbents. One way to indirectly determine the uptake capacity of a PAS is to establish an uptake curve for a period longer than the linear uptake period. Somewhat surprisingly, studies to determine uptake curves have rarely been performed and most studies on PASs for GEM have relied on a single (possibly replicated) length of deployment. Specifically, what has been rare in the literature are uptake experiments involving the simultaneous deployment of multiple samplers (including sample replication) for variable time periods and the plotting of an uptake curve displaying adsorbed amounts versus deployment time. Mniszek (2001) did expose eight samplers simultaneously for periods ranging from 1 to $8 \mathrm{~h}$, yielding highly linear uptake curves (Fig. 5a); however, the short overall deployment period prevents the derivation of information on the PAS's uptake capacity. Nishikawa et al. (1999) conducted a rudimentary uptake experiment, which involved exposures of 11 and 126 days for two different lengths of their diffusor tube (3 and $30 \mathrm{~mm}$ ) and uptake curves appear to be linear over such a long time (Fig. 5b). Brumbaugh et al. (2000) sampled over 4, 8, and 12 weeks outdoors. While the data (Fig. 5c) do suggest reasonably linear uptake, GEM concentrations during the deployment were not recorded. Brumbaugh et al. (2000) also investigated whether the SR depends on the length of PAS exposure by comparing day-long with weeklong deployments. SRs after 1 week were slightly, but consistently, lower by $16.5 \%$ than after $24 \mathrm{~h}$, suggesting that the sampler's linear uptake phase is shorter than a week.

We suspect that some of the scatter in Fig. 4 is due to a low, irreproducible, and/or unstable uptake capacity of the employed metal sorbents, in addition to poorly constrained SRs. In particular, passivation, memory effects, and physical degradation affect the performance of gold-based sorbents over extended deployments. Passivation occurs when GEM binding sites on a sorbent become obscured by interfering compounds or when reactions between atmospheric constituents and sorbed $\mathrm{Hg}$ strip some of the analyte from the sorbent over time (Gustin et al., 2011; Huang et al., 2012; Mattoli et al., 2007). While silver and gold sorbents can both undergo passivation, complexes between atmospheric interferents and silver are typically more stable than those with gold (Gustin et al., 2011). Elevated levels of chlorinated and sulfonated compounds in the atmosphere affect noble metal 
PAS uptake the most (Brown et al., 2012; Mattoli et al., 2007; McCammon and Woodfin, 1977; Luo et al., 2010). Furthermore, passivation of gold tends to increase with increasing deployment time and $\mathrm{Hg}$ concentration (Gustin et al., 2011). Passivation may thus reduce the maximum possible deployment period of a PAS and, if interferents are not completely removed in analysis, the sorbent's long-term regeneration capacity is reduced.

Conceivably, passivation could also occur with other sorbents. The relatively high number of active sites on activated carbon should reduce the effect of passivation, but research to date has been inconclusive. Diamantopoulou et al. (2010) reported that while $\mathrm{HCl}, \mathrm{SO}_{2}$, and $\mathrm{O}_{2}$ enhanced GEM uptake to virgin activated carbons, $\mathrm{CO}_{2}$ inhibited it. These experiments were conducted at elevated concentrations and temperatures relevant to $\mathrm{Hg}$ sequestration from flue stack emissions (Diamantopoulou et al., 2010). While the concentrations of potentially interfering compounds in ambient air will be much lower, this is nonetheless a concern that may require experimentation at interferent concentrations, temperatures, and humidities relevant to actual deployments of PASs.

Memory effects, or the potential to retain residual $\mathrm{Hg}$ after thermal desorption, may also compromise sampler accuracy (Brown et al., 2001, 2012; Luo et al., 2010). Memory effects have been estimated to contribute between 0.1 and $5 \%$ error to individual measurements (Brown et al., 2011; Luo et al., 2010). Brown et al. (2011) observed both short-term and long-term memory effects in the analysis of gold sorbent sampling tubes deployed for 1 to 4 weeks in an active sampler. Short-term memory effects occur when $\mathrm{Hg}$ is insufficiently flushed from the sorbent during desorption (Brown et al., 2011) and can be addressed through the use of properly tuned desorption cycles that maximize the recovery of sorbed $\mathrm{Hg}$ by ensuring flow rate, desorption temperature, and duration are sufficient to flush all $\mathrm{Hg}$ from the sorbent (Brown et al., 2011; Luo et al., 2010; Skov et al., 2007). Long-term memory effects occur when $\mathrm{Hg}$, especially in its oxidized forms (Brown et al., 2011; Morris et al., 2002; Nowakowski et al., 1997), diffuses from surface sorption sites into the bulk material (Brown et al., 2011; Dumarey et al., 1985; Luo et al., 2010). Brown et al. (2011) proposed that the diffusion of $\mathrm{Hg}$ into the bulk material may actually be facilitated by thermal desorption and not occur during sampling. They suggest that two analytical desorption cycles be applied with a delay of approximately 20 days between cycles to allow $\mathrm{Hg}$ in the bulk material to migrate back to the surface and, hence, allow the determination of all sampled $\mathrm{Hg}$ (Brown et al., 2011). Alternatively, managing sorbents through deployment only in environments of consistent GEM concentrations (not using the same sorbent at a point source site then at a background site), over consistent deployment times, is likely to reduce or remove the long-term memory effect altogether (Brown et al., 2011). This is due to a consistent amount of Hg migrating into and out of the bulk sorbent during desorption and deployment respectively when GEM concentrations during deployments are similar (Brown et al., 2011).

Physical degradation of the sorbent may interfere with the accuracy of measurements, particularly in the case of sorbent material reuse. With time and repeated use, sorbent coatings of noble metals onto inert substrates will slowly lose their structural integrity and partially disintegrate, resulting in the addition of particulate matter to the analysis stream (Brown et al., 2011). While the exact nature of this particle interference is unknown, it has been suggested that there may be some interaction between the desorbed GEM and the sorbent particles in the gas stream that may interfere with the analysis (Brown et al., 2011). In order to minimize these effects, careful accounting of age, condition, and changes in desorption and analysis characteristics should help to identify problematic samplers.

\subsection{Are existing gaseous elemental mercury passive air samplers inexpensive and simple?}

Noble metal, especially gold-based, sorbents are relatively expensive. This is certainly the case when these materials are used in solid forms as in the PAS by Skov et al. (2007). Activated carbon is a low-cost material, particularly when considering the small amount of material required per sampler (Zhang et al., 2012, used approx. $1 \mathrm{~g}$ of carbon per sampler). However, analytical methods for activated carbon are destructive by nature (Zhang et al., 2012), while analysis of noble metals also regenerates the sorbent, allowing re-deployment. This potentially mitigates elevated material costs for noble metals. Sorbent analysis may be a considerable expense as well. The costs associated with sampler housings (and external shields) must also be considered, and while commercially available diffusive barriers such as the Radiello ${ }^{\circledR}$ tested by Skov et al. (2007) and Gustin et al. (2011) reduce quality control issues they are also likely to increase the cost of the PAS. Overall, the cost of existing designs is presumably quite low, possibly with the exception of the sampler by Skov et al. (2007). It also appears that manufacture, deployment, retrieval, and storage of existing PAS is generally simple, although handling of the liquid-filled tube of the sampler by Brumbaugh et al. (2000) is more challenging.

\subsection{General reflection on existing gaseous elemental mercury passive air samplers}

At the present time, existing GEM PASs do not appear to have the precision and accuracy that is required to distinguish between the relative small concentration differences that can be expected between background sites. In particular, samplers relying on gold-based sorbents struggle with low, variable, and/or deteriorating uptake capacity and SR inconsistencies, especially over longer deployments, due to issues such as passivation and memory effects. While activated car- 
bon overcomes some of the problems of gold-based sorbent, the SR of the carbon-based PAS by Zhang et al. (2012) is influenced by wind. While few samplers have succeeded in completely eliminating the effect of wind on uptake kinetics, the SR of samplers incorporating a diffusive barrier and/or a long and narrow diffusion tube can be expected to be less susceptible to wind. The high sensitivity of the analytical techniques typically used for $\mathrm{Hg}$ quantification may allow for sampler designs that sacrifice a relatively high SR in order to reduce the effect of wind. One of the major failings of research to date has been the limited use of uptake experiments in GEM PAS testing involving the simultaneous deployment of multiple samplers for variable time periods. Uptake curves enable the effective deployment period and the uptake capacity of the sampler to be determined as well as the SR if active measurements are also taken.

\section{Future perspectives}

\subsection{Novel sorbent materials}

The development of new Hg sorbents has largely been motivated by $\mathrm{Hg}$ emission control technology development for coal combustion. Zhang et al. (2012) introduced sulfurimpregnated activated carbon as a sorbent suitable for passive GEM sampling. Given the positive results, it is likely that activated carbon-based PASs for GEM will be further developed in the future, particularly for longer-term deployments. A variety of virgin and impregnated activated carbons exist, and those that are most successful in sequestering $\mathrm{Hg}$ from flue stacks may also hold most promise as GEM PAS sorbents. It may be possible to enhance the sorptive properties of commercially available carbon for GEM. For example, greater GEM sorption in a virgin activated carbon impregnated with sulfur than for a commercially available sulfurimpregnated product has previously been reported (Vidic et al., 1998; Vidic and McLaughlin, 1996).

Although noble metals perform well during the amalgamation of GEM in active air monitoring systems and in other Hg-related analytical instruments, their use in PASs so far has not been convincing, largely because of sorbent passivation. It is possible that the large surface area to volume ratio created by nanostructured gold and silver sorbents (James et al., 2012; Liu et al., 2008) could mitigate the effects of passivation due to the sheer abundance of available binding sites. Hence nanostructured sorbents may have better performance in GEM PASs than noble metal sorbents in more traditional forms. Liu et al. (2008) coated chabazite (aluminum-silicate) nanoparticles of high polarity with silver, yielding a nano-sorbent with a high reactivity with $\mathrm{Hg}$ and thus high uptake. Similarly, James et al. (2012) successfully measured the uptake of GEM onto commercially available 4-tert-butylthiophenol functionalized $2-5 \mathrm{~nm}$ gold nanoparticles using shifts in the characteristic localized sur- face plasmon resonance of the gold nanoparticles caused by sorbed $\mathrm{Hg}$. The ability of these sorbents to regenerate was excellent; Liu et al. (2008) reported 96.9-102.9\% GEM recovery over 15 sorption and desorption cycles under the same GEM concentrations and James et al. (2012) determined no reduction in signal even after 30 regenerations. It is possible, however, that more binding sites may simply equate to more sites for passivation and further testing is required to confirm the relevance of nanostructured sorbents for GEM PASs. Other considerations that need to be addressed in the application of nanotechnology to passive $\mathrm{Hg}$ sampling are the high costs of commercially available nanostructures and potential inconsistencies in the reproducibility of nanostructure synthesis and substrate attachment (Fraunhofer et al., 2004).

\subsection{Lessons from active monitoring}

Active air sampling techniques for GEM share many characteristics with PAS methods. Active samplers utilize gold cartridges, which collect ambient air at a given flow rate over the course of deployment and are analysed in situ by CVAFS (Brown et al., 2011). The work by Brown et al. (2011) on the issue of memory effects in gold sorbents is applicable to PASs for GEM due to the widespread use of similar sorbents. Furthermore, handling and analysis techniques used in active samplers can, in many cases, be directly imported to research using a single PAS or even a network of the devices, assisting in the minimization of systematic errors. Among the many recommendations put forward, one of the most crucial is network planning. That involves the development of PAS histories for repetitively deployed PASs, with the long-term goal of eventually establishing PAS cohorts that can be used interchangeably at sites with similar expected concentrations (Brown et al., 2011). In doing so, variations in PAS measurements as a result of memory effects are minimized due to the near constant carry-over of $\mathrm{Hg}$ diffusing into the bulk gold between samples (Brown et al., 2011).

\subsection{Establishing testing protocols}

The testing of existing PAS designs has varied considerably from one device to the next, making PAS comparison problematic. Although opinions on exactly how to test the various factors that influence PAS measurements may differ, establishing a list of factors that require testing would likely facilitate sampler comparisons and in turn enhance future research in the field. Ideally, SRs should be estimated theoretically from the sampler design as well as being determined by calibration using a recognized active air monitoring system under both controlled, stable conditions and environmentally relevant conditions. As suggested by Gustin et al. (2011) the comparison of theoretical and measured SRs would immediately identify PAS inefficiencies. However, theoretical or modelled assessments of SRs must have low uncertainties for this to be the case. Indeed, not accounting for reduced 
SRs caused by the "tortuous" path taken by molecules diffusing through the porous barrier may have been a substantial contributor to the discrepancies between theoretical and calibrated SRs in certain PAS designs (e.g. Brown et al., 2012; Gustin et al., 2011; Skov et al., 2007). The influence of meteorological factors should be isolated and examined individually. Uptake curves should be computed for all PASs as they allow not only the determination of effective deployment time ranges but also the potential to ascertain uptake capacities of the sampler sorbents. Furthermore, if the PAS is designed for outdoor deployment, thorough testing across the full range of the conditions a PAS may experience should be undertaken along with simultaneous measurements from an active air monitoring system to assess calibrated SRs and the sampler's effectiveness in realistic settings. Finally, it is important for each specific sampler to attempt to determine the exact species of $\mathrm{Hg}$ being sampled (GEM, TGM, or even TGM + PBM). This may be tested in the laboratory or by sampling alongside an automated $\mathrm{Hg}$ speciation sampler at sites where GOM and/or PBM are known to be elevated in proportion to GEM, such as coastal polar locations.

\section{Data availability}

This critical review contains no new data. All data from tables and figures were obtained from data in existing research papers.

Acknowledgements. We acknowledge funding from Environment Canada, a Strategic Project Grant from the Natural Sciences and Engineering Research Council of Canada, and Yukon College.

The authors declare no competing financial interest.

Edited by: L. Zhang

\section{References}

AMAP: Assessment 2011: Mercury in the Arctic, Arctic Monitoring and Assessment Programme Oslo, Norway/Geneva Switzerland, 193 pp., 2011.

AMAP/UNEP: Technical Background Report for the Global Mercury Assessment 2013, Arctic Monitoring and Assessment Programme/United Nations Environment Programme, Oslo, Norway/Geneva, Switzerland, 263 pp., 2013.

Barbosa, A., De Souza, J., Dorea, J., Jardim, W., and Fadini, P.: Mercury biomagnification in a tropical black water, Rio Negro, Brazil, Arch. Environ. Con. Tox., 45, 235-246, 2003.

Bartkow, M. E., Booij, K., Kennedy, K. E., Müller, J. F., and Hawker, D. W.: Passive air sampling theory for semivolatile organic compounds, Chemosphere, 60, 170-176, doi:10.1016/j.chemosphere.2004.12.033, 2005.

Bohlin, P., Jones, K. C., and Strandberg, B.: Occupational and indoor air exposure to persistent organic pollutants: A review of passive sampling techniques and needs, J. Environ. Monitor., 9, 501-509, 2007
Brown, R. J. C., Kumar, Y., Brown, A. S., and Kim, K.-H.: Memory effects on adsorption tubes for mercury vapor measurement in ambient air: elucidation, quantification, and strategies for mitigation of analytical bias, Environ. Sci. Technol., 45, 7812-7818, 2011.

Brown, R. J. C., Burdon, M. K., Brown, A. S., and Kim, K.-H.: Assessment of pumped mercury vapour adsorption tubes as passive samplers using a micro-exposure chamber, J. Environ. Monitor., 14, 2456-2463, doi:10.1039/C2EM30101F, 2012.

Brumbaugh, W. G., Petty, J. D., May, T. W., and Huckins, J. N.: A passive integrative sampler for mercury vapor in air and neutral mercury species in water, Chemosphere, 2, 1-9, doi:10.1016/S1465-9972(99)00055-0, 2000.

Carpi, A.: Mercury from combustion sources: a review of the chemical species emitted and their transport in the atmosphere, Water Air Soil Poll., 98, 241-254, doi:10.1007/BF02047037, 1997.

Carpi, A. and Chen, Y.-F.: Gaseous elemental mercury as an indoor air pollutant, Environ. Sci. Technol., 35, 4170-4173, doi:10.1021/es010749p, 2001.

Cheng, I., Zhang, L., Mao, H., Blanchard, P., Tordon, R., and Dalziel, J.: Seasonal and diurnal patterns of speciated atmospheric mercury at a coastal-rural and a coastal-urban site, Atmos. Environ., 82, 193-205, 2014.

Diamantopoulou, I., Skodras, G., and Sakellaropoulos, G. P.: Sorption of mercury by activated carbon in the presence of flue gas components, Fuel Process. Technol., 91, 158-163, doi:10.1016/j.fuproc.2009.09.005, 2010.

Dommergue, A., Sprovieri, F., Pirrone, N., Ebinghaus, R., Brooks, S., Courteaud, J., and Ferrari, C. P.: Overview of mercury measurements in the Antarctic troposphere, Atmos. Chem. Phys., 10, 3309-3319, doi:10.5194/acp-10-3309-2010, 2010.

Driscoll, C. T., Mason, R. P., Chan, H. M., Jacob, D. J., and Pirrone, N.: Mercury as a global pollutant: sources, pathways, and effects, Environ. Sci. Technol., 47, 4967-4983, 2013.

Dumarey, R., Dams, R., and Hoste, J.: Comparison of the collection and desorption efficiency of activated charcoal, silver, and gold for the determination of vapor-phase atmospheric mercury, Anal. Chem., 57, 2638-2643, 1985.

Ebinghaus, R., Jennings, S., Schroeder, W., Berg, T., Donaghy, T., Guentzel, J., Kenny, C., Kock, H., Kvietkus, K., and Landing, W.: International field intercomparison measurements of atmospheric mercury species at Mace Head, Ireland, Atmos. Environ., 33, 3063-3073, 1999.

Ebinghaus, R., Kock, H., Coggins, A., Spain, T., Jennings, S., and Temme, C.: Long-term measurements of atmospheric mercury at Mace Head, Irish west coast, between 1995 and 2001, Atmos. Environ., 36, 5267-5276, 2002.

European Commission: Council Directive 2004/107/EC of the European Parliament and of the Council of 15 December 2004 relating to arsenic, cadmium, mercury, nickel and polycyclic aromatic hydrocarbons in ambient air, O. J. L., 23, 3-16, 2005.

Fraunhofer, W., Winter, G., and Coester, C.: Asymmetrical flow field-flow fractionation and multiangle light scattering for analysis of gelatin nanoparticle drug carrier systems, Anal. Chem., 76, 1909-1920, doi:10.1021/ac0353031, 2004.

Govt. of Canada: Canadian Arctic Contaminants Assessment Report III 2012: Mercury in Canada's North, Govt. of Canada, Department of Aboriginal Affairs and Northern Development, Ottawa, Ontario, Canada, 2012. 
Greaves, E. D., Alfonso Sosa, J., Sajo-Bohus, L., Alvarez, M., Wobrauschek, P., and Streli, C.: Trace element determination of mercury by total-reflection X-ray fluorescence, Spectrochim. Acta B, 52, 945-951, doi:10.1016/S0584-8547(97)00001-3, 1997.

Guo, H., Lin, H., Zhang, W., Deng, C., Wang, H., Zhang, Q., Shen, Y., and Wang, X.: Influence of meteorological factors on the atmospheric mercury measurement by a novel passive sampler, Atmos. Environ., 97, 310-315, 2014.

Gustin, M. and Jaffe, D.: Reducing the uncertainty in measurement and understanding of mercury in the atmosphere, Environ. Sci. Technol., 44, 2222-2227, 10.1021/es902736k, 2010.

Gustin, M. S., Lyman, S. N., Kilner, P., and Prestbo, E.: Development of a passive sampler for gaseous mercury, Atmos. Environ., 45, 5805-5812, doi:10.1016/j.atmosenv.2011.07.014, 2011.

Harari, R., Harari, F., Gerhardsson, L., Lundh, T., Skerfving, S., Strömberg, U., and Broberg, K.: Exposure and toxic effects of elemental mercury in gold-mining activities in Ecuador, Toxicol. Lett., 213, 75-82, doi:10.1016/j.toxlet.2011.09.006, 2012.

Hayward, S. J., Gouin, T., and Wania, F.: Comparison of four active and passive sampling techniques for pesticides in air, Environ. Sci. Technol., 44, 3410-3416, doi:10.1021/es902512h, 2010.

Huang, J., Choi, H.-D., Landis, M. S., and Holsen, T. M.: An application of passive samplers to understand atmospheric mercury concentration and dry deposition spatial distributions, J. Environ. Monitor., 14, 2976-2982, doi:10.1039/C2EM30514C, 2012.

Huang, J., Lyman, S. N., Hartman, J. S., and Gustin, M. S.: A review of passive sampling systems for ambient air mercury measurements, Environ. Sci. Process Impacts, 16, 374-392, 2014.

James, J. Z., Lucas, D., and Koshland, C. P.: Gold nanoparticle films as sensitive and reusable elemental mercury sensors, Environ. Sci. Technol., 46, 9557-9562, doi:10.1021/es3005656, 2012.

Johansen, P., Mulvad, G., Pedersen, H. S., Hansen, J. C., and Riget, F.: Human accumulation of mercury in Greenland, Sci. Total Environ., 377, 173-178, 2007.

Karatza, D., Lancia, A., Musmarra, D., Pepe, F., and Volpicelli, G.: Removal of mercuric chloride from flue gas by sulfur impregnated activated carbon, Hazard. Waste Hazard., 13, 95-105, 1996.

Karatza, D., Lancia, A., Musmarra, D., and Zucchini, C.: Study of mercury absorption and desorption on sulfur impregnated carbon, Exp. Therm. Fluid Sci., 21, 150-155, doi:10.1016/S08941777(99)00065-5, 2000.

Keeler, G. J., Pirrone, N., Bullock, R., and Sillman, S.: The need for a coordinated global mercury monitoring network for global and regional models validations, in: Mercury fate and transport in the global atmosphere: emissions, measurements and models edited by: Pirrone, N. and Mason, R., Springer, Dordrecht, 391-424, 2009.

Kellerhals, M., Beauchamp, S., Belzer, W., Blanchard, P., Froude, F., Harvey, B., McDonald, K., Pilote, M., Poissant, L., and Puckett, K.: Temporal and spatial variability of total gaseous mercury in Canada: results from the Canadian Atmospheric Mercury Measurement Network (CAMNet), Atmos. Environ., 37, 10031011, 2003.

Kock, H. H., Bieber, E., Ebinghaus, R., Spain, T. G., and Thees, B.: Comparison of long-term trends and seasonal variations of atmospheric mercury concentrations at the two European coastal monitoring stations Mace Head, Ire- land, and Zingst, Germany, Atmos. Environ., 39, 7549-7556, doi:10.1016/j.atmosenv.2005.02.059, 2005.

Król, S., Zabiegała, B., and Namieśnik, J.: Monitoring VOCs in atmospheric air II. Sample collection and preparation, TRACTrend. Anal. Chem., 29, 1101-1112, 2010.

Lee, S. H., Rhim, Y. J., Cho, S. P., and Baek, J. I.: Carbon-based novel, Fuel, 85, 219-226, doi:10.1016/j.fuel.2005.02.030, 2006.

Levy, W., Henkelmann, B., Pfister, G., Bernhöft, S., Kirchner, M., Jakobi, G., Bassan, R., Kräuchi, N., and Schramm, K. W.: Longterm air monitoring of organochlorine pesticides using semi permeable membrane devices (SPMDs) in the Alps, Environ. Pollut., 157, 3272-3279, doi:10.1016/j.envpol.2009.05.043, 2009.

Lin, C.-J., Pongprueksa, P., Lindberg, S. E., Pehkonen, S. O., Byun, D., and Jang, C.: Scientific uncertainties in atmospheric mercury models I: model science evaluation, Atmos. Environ., 40, 29112928, doi:10.1016/j.atmosenv.2006.01.009, 2006.

Liu, Y., Kelly, D. J., Yang, H., Lin, C. C., Kuznicki, S. M., and $\mathrm{Xu}, \mathrm{Z}$.: Novel regenerable sorbent for mercury capture from flue gases of coal-fired power plant, Environ. Sci. Technol., 42, 62056210, 2008.

Liu, Y., Zhan, Z., Du, F., Kong, S., and Liu, Y.: Indoor air concentrations of mercury species in incineration plants for municipal solid waste (MSW) and hospital waste (HW), Chemosphere, 75, 266-271, doi:10.1016/j.chemosphere.2008.11.079, 2009.

Luo, G., Yao, H., Xu, M., Cui, X., Chen, W., Gupta, R., and Xu, Z.: Carbon nanotube-silver composite for mercury capture and analysis, Energ. Fuel., 24, 419-426, doi:10.1021/ef900777v, 2010.

Lynam, M. M. and Keeler, G. J.: Comparison of methods for particulate phase mercury analysis: sampling and analysis, Anal. Bioanal. Chem., 374, 1009-1014, 2002.

Lyman, S. N. and Gustin, M. S.: Speciation of atmospheric mercury at two sites in northern Nevada, USA, Atmos. Environ., 42, 927939, 2008.

Lyman, S. N., Gustin, M. S., and Prestbo, E. M.: A passive sampler for ambient gaseous oxidized mercury concentrations, Atmos. Environ., 44, 246-252, doi:10.1016/j.atmosenv.2009.10.008, 2010.

Malm, O., Castro, M. B., Bastos, W. R., Branches, F. J. P., Guimarães, J. R. D., Zuffo, C. E., and Pfeiffer, W. C.: An assessment of $\mathrm{Hg}$ pollution in different goldmining areas, Amazon Brazil, Sci. Total Environ., 175, 127-140, 1995.

Mattoli, V., Mazzolai, B., Raffa, V., Mondini, A., and Dario, P.: Design of a new real-time dosimeter to monitor personal exposure to elemental gaseous mercury, Sensor. Actuat. B-Chem., 123, 158167, doi:10.1016/j.snb.2006.08.004, 2007.

May, A. A., Ashman, P., Huang, J., Dhaniyala, S., and Holsen, T. M.: Evaluation of the polyurethane foam (PUF) disk passive air sampler: computational modeling and experimental measurements, Atmos. Environ., 45, 4354-4359, doi:10.1016/j.atmosenv.2011.05.052, 2011.

McCammon, C. S. and Woodfin, J. W.: An evaluation of a passive monitor for mercury vapor, Am. Ind. Hyg. Assoc. J., 38, 378386, 1977.

Mniszek, W.: Exposure assessment to mercury vapor in chloralkali industry, Environ. Monitor. Assess., 68, 197-207, 2001.

Moeckel, C., Harner, T., Nizzetto, L., Strandberg, B., Lindroth, A., and Jones, K. C.: Use of depuration compounds in passive air samplers: Results from active sampling-supported field deploy- 
ment, potential uses, and recommendations, Environ. Sci. Technol., 43, 3227-3232, 2009.

Morris, T., Kloepper, K., Wilson, S., and Szulczewski, G.: A spectroscopic study of mercury vapor adsorption on gold nanoparticle films, J. Colloid Interf. Sci., 254, 49-55, 2002.

Munthe, J., Wängberg, I., Pirrone, N., Iverfeldt, Å., Ferrara, R., Ebinghaus, R., Feng, X., Gårdfeldt, K., Keeler, G., Lanzillotta, E., Lindberg, S. E., Lu, J., Mamane, Y., Prestbo, E., Schmolke, S., Schroeder, W. H., Sommar, J., Sprovieri, F., Stevens, R. K., Stratton, W., Tuncel, G., and Urba, A.: Intercomparison of methods for sampling and analysis of atmospheric mercury species, Atmos. Environ., 35, 3007-3017, doi:10.1016/S13522310(01)00104-2, 2001

Nguyen, H. T., Kim, K.-H., Shon, Z.-H., and Hong, S.: A review of atmospheric mercury in the polar environment, Crit. Rev. Env. Sci. Tec., 39, 552-584, 2009.

Nishikawa, M., Shiraishi, H., Yanase, R., and Tanida, K.: Examination of an improved passive sampler for gaseous mercury on the landfill site, J. Environ. Chem., 9, 681-684, 1999.

Nowakowski, R., Kobiela, T., Wolfram, Z., and Duś, R.: Atomic force microscopy of $\mathrm{AuHg}$ alloy formation on thin $\mathrm{Au}$ films, Appl. Surf. Sci., 115, 217-231, 1997.

Pandey, S. K., Kim, K.-H., and Brown, R. J. C.: Measurement techniques for mercury species in ambient air, TRAC-Trend. Anal. Chem., 30, 899-917, doi:10.1016/j.trac.2011.01.017, 2011.

Pennequin-Cardinal, A., Plaisance, H., Locoge, N., Ramalho, O., Kirchner, S., and Galloo, J.-C.: Performances of the Radiello diffusive sampler for BTEX measurements: Influence of environmental conditions and determination of modelled sampling rates, Atmos. Environ., 39, 2535-2544, doi:10.1016/j.atmosenv.2004.12.035, 2005.

Peterson, C., Alishahi, M., and Gustin, M. S.: Testing the use of passive sampling systems for understanding air mercury concentrations and dry deposition across Florida, USA, Sci. Total Environ., 424, 297-307, 2012.

Pirrone, N., Cinnirella, S., Feng, X., Finkelman, R. B., Friedli, H. R., Leaner, J., Mason, R., Mukherjee, A. B., Stracher, G. B., Streets, D. G., and Telmer, K.: Global mercury emissions to the atmosphere from anthropogenic and natural sources, Atmos. Chem. Phys., 10, 5951-5964, doi:10.5194/acp-10-59512010, 2010.

Pirrone, N., Aas, W., Cinnirella, S., Ebinghaus, R., Hedgecock, I. M., Pacyna, J., Sprovieri, F., and Sunderland, E. M.: Toward the next generation of air quality monitoring: mercury, Atmos. Environ., 80, 599-611, doi:10.1016/j.atmosenv.2013.06.053, 2013.

Plaisance, H., Sagnier, I., Saison, J., Galloo, J., and Guillermo, R.: Performances and application of a passive sampling method for the simultaneous determination of nitrogen dioxide and sulfur dioxide in ambient air, Environ. Monitor. Assess., 79, 301-315, 2002.

Prokopowicz, A. and Mniszek, W.: Mercury vapor determination in hospitals, Environ. Monitor. Assess., 104, 147-154, doi:10.1007/s10661-005-1606-8, 2005.

Renner, R.: EPA to strengthen persistent, bioaccumulative, and toxic pollutant controls - mercury first to be targeted, Environ. Sci. Technol., 33, 62A-62A, 1999.

Rex, M., Hernandez, F. E., and Campiglia, A. D.: Pushing the limits of mercury sensors with gold nanorods, Anal. Chem., 78, 445$451,2006$.
Scheuhammer, A. M., Meyer, M. W., Sandheinrich, M. B., and Murray, M. W.: Effects of environmental methylmercury on the health of wild birds, mammals, and fish, AMBIO, 36, 12-19, doi:10.1579/0044-7447(2007)36[12:EOEMOT]2.0.CO;2, 2007.

Schroeder, W., Keeler, G., Kock, H., Roussel, P., Schneeberger, D., and Schaedlich, F.: International field intercomparison of atmospheric mercury measurement methods, Water Air Soil Poll., 80, 611-620, 1995.

Schroeder, W. H. and Munthe, J.: Atmospheric mercury - an overview, Atmos. Environ., 32, 809-822, 1998.

Selin, N. E.: Global biogeochemical cycling of mercury: a review, Annu. Rev. Env. Resour., 34, 43-63, doi:10.1146/annurev.environ.051308.084314, 2009.

Selin, N. E., Jacob, D. J., Park, R. J., Yantosca, R. M., Strode, S., Jaeglé, L., and Jaffe, D.: Chemical cycling and deposition of atmospheric mercury: global constraints from observations, J. Geophys. Res.-Atmos., 112, D02308, doi:10.1029/2006JD007450, 2007.

Shoeib, M. and Harner, T.: Characterization and comparison of three passive air samplers for persistent organic pollutants, Environ. Sci. Technol., 36, 4142-4151, 2002.

Skov, H., Christensen, J. H., Goodsite, M. E., Heidam, N. Z., Jensen, B., Wåhlin, P., and Geernaert, G.: Fate of elemental mercury in the Arctic during atmospheric mercury depletion episodes and the load of atmospheric mercury to the Arctic, Environ. Sci. Technol., 38, 2373-2382, 2004.

Skov, H., Sørensen, B. T., Landis, M. S., Johnson, M. S., Sacco, P., Goodsite, M. E., Lohse, C., and Christiansen, K. S.: Performance of a new diffusive sampler for $\mathrm{Hg} 0$ determination in the troposphere, Environ. Chem., 4, 75-80, doi:10.1071/EN06082, 2007.

Sousa, R. N. and Veiga, M. M.: Using performance indicators to evaluate an environmental education program in artisanal gold mining communities in the Brazilian Amazon, AMBIO, 38, 4046, 2009.

Sprovieri, F., Pirrone, N., Ebinghaus, R., Kock, H., and Dommergue, A.: A review of worldwide atmospheric mercury measurements, Atmos. Chem. Phys., 10, 8245-8265, doi:10.5194/acp10-8245-2010, 2010.

Suresh Kumar Reddy, K., Al Shoaibi, A., and Srinivasakannan, C.: Elemental mercury adsorption on sulfur-impregnated porous carbon - A review, Environ. Technol., 35, 1-9, doi:10.1080/21622515.2013.804589, 2013.

Tian, W., Egeland, G. M., Sobol, I., and Chan, H. M.: Mercury hair concentrations and dietary exposure among Inuit preschool children in Nunavut, Canada, Environ. Int., 37, 42-48, 2011.

UNEP: Minamata Convention on Mercury: Text and Annexes, United Nations Environmental Programme, Geneva, Switzerland, 67 pp., 2013.

Vidic, R. D. and McLaughlin, J. B.: Uptake of elemental mercury vapors by activated carbons, J. Air Waste Manage., 46, 241-250, 10.1080/10473289.1996.10467458, 1996.

Vidic, R. D. and Siler, D. P.: Vapor-phase elemental mercury adsorption by activated carbon impregnated with chloride and chelating agents, Carbon, 39, 3-14, doi:10.1016/S00086223(00)00081-6, 2001.

Vidic, R. D., Chang, M.-T., and Thurnau, R. C.: Kinetics of vaporphase mercury uptake by virgin and sulfur-impregnated activated carbons, J. Air Waste Manage., 48, 247-255, 1998. 
Wheatley, B. and Wheatley, M. A.: Methylmercury and the health of indigenous peoples: a risk management challenge for physical and social sciences and for public health policy, Sci. Total Environ., 259, 23-29, 2000.

Wolfe, M. F., Schwarzbach, S., and Sulaiman, R. A.: Effects of mercury on wildlife: a comprehensive review, Environ. Toxicol. Chem., 17, 146-160, 1998.

Xiao, H., Hung, H., Harner, T., Lei, Y. D., Johnstone, G. W., and Wania, F.: A flow-through sampler for semi-volatile organic compounds in air, Environ. Sci. Technol., 41, 250-256, 2007.

Zhang, L. and Wong, M. H.: Environmental mercury contamination in China: sources and impacts, Environ. Int., 33, 108-121, doi:10.1016/j.envint.2006.06.022, 2007.
Zhang, W., Tong, Y., Hu, D., Ou, L., and Wang, X.: Characterization of atmospheric mercury concentrations along an urban-rural gradient using a newly developed passive sampler, Atmos. Environ., 47, 26-32, doi:10.1016/j.atmosenv.2011.11.046, 2012.

Zielonka, U., Krupanek, J., Suschka, J., Worsztynowicz, A., and Dzialoszyńska-Wawrzkiewicz, M.: An inventory and assessment of options for reducing emissions: mercury, Source Control of Priority Substances in Europe, Katowice, Poland, 51 pp., 2012. 